\title{
A FERRAMENTA VÍDEO PARA A EAD - A GRAVAÇÃO DE AULA PARA O FORMATO EM EAD
}

\author{
SÃO PAULO/SP MAIO/2018
}

\author{
Alonso Thuler de Souza - UBC - alonso.souza@brazcubas.br \\ Eliziane Jacqueline dos Santos Inácio Ferreira - UBC - eliziane.santos@brazcubas.br \\ Marina Mariko Adatt Hardt $\quad$ - UBC - marina.hardt@brazcubas.br \\ Robson Paz Vieira - UBC - robson.vieira@brazcubas.br
}

Tipo: Investigação Científica (IC)

Natureza: Relatório Final de Pesquisa

Categoria: Conteúdos e Habilidades

Setor Educacional: EDUCAÇÃO SUPERIOR

\begin{abstract}
RESUMO
O presente trabalho tem como objetivo, abordar as gravações de vídeos utilizados na plataforma EaD para levar conhecimento ao estudante. No processo desenvolvido, encontra-se alguns problemas referentes à nomenclatura tele aula, processo utilizado por uma universidade no Estado de São Paulo. A forma de verificação será abordada por meio de análise do processo desde a produção do conteúdo até a entrega final e a utilização de leitura bibliográfica com referências entre artigos e leituras específicas da área de comunicação. Entretanto, é preciso analisar os materiais elaborados como referência e modelo e o vídeo que é oferecido pela Instituição de Ensino.
\end{abstract}

Palavras-chave: : Educação à distância, material educativo, vídeo, tele aula, videoaula

\section{AGRADECIMENTOS}

AGRADECIMENTO AOS PROFESSORES DA PÓS-GRADUAÇÃO. 


\section{INTRODUÇÃO}

Que a Educação à Distância chegou a todos os cantos e em todos os níveis da educação no Brasil, isso já sabemos. Falta agora aprimorar os processos educacionais e pedagógicos para procurar oferecer sempre algo mais educativo e inovador na questão da construção do conhecimento do estudante. As instituições de ensino que visam qualidade de forma intrínseca perceberam que com o amadurecimento dos órgãos que regulamentam o ensino e uma aceitação de um público que busca essa modalidade de educação, fornecem materiais cada vez mais oportunos e atraentes com as novas possibilidades de tecnologia de informação e as chamadas ferramentas digitais.

Sendo assim, é de extrema importância os profissionais que planejam os materiais utilizados pelo professor, precisam ser capacitados e dominar as ferramentas para criar conteúdos diferentes e inovadores. Deste modo, além de uma equipe com profissionais qualificados e condições técnicas plenas, a tendência é que a produção audiovisual seja eficiente e de boa qualidade. Para isso, é fundamental que o professor, elemento mais importante nesta concepção, também deve ser preparado e entender como funciona todo o processo desde a elaboração do material até a entrega dos trabalhos na plataforma que é disponibilizada ao aluno.

Se tratando de vídeo é importante entender que a captação é feito por lentes de câmeras que registram a imagem quer será gravada. Na parte histórica a fotografia e o cinema são importantes para entendermos o processo que levou a $\mathrm{EaD}$ a utilizar os vídeos. Neste caso, surgem nomenclaturas como tele aula, videoaula e web aula. Vamos analisar cada uma delas e ver qual o melhor formato para ser utilizado por essa universidade. Assim, o estudo irá nos levar a contextualizações voltadas para o conhecimento da linguagem adotada, os formatos de gravação e o meio de mensagem como processo cognitivo.

\section{DESENVOLVIMENTO}

De acordo como os Referenciais de Qualidade para Educação Superior à Distância (2015), "não há um modelo único de educação à distância". E sendo que o próprio órgão que regulamenta o serviço não elabora um modelo prático para que todos possam usar como referências, cada instituição elabora o próprio projeto pedagógico, dentre, do que apenas o MEC, órgão que regulamenta o ensino no Brasil apenas exige.

Sendo assim, pode-se destacar que quando uma instituição de ensino inicia um projeto 
pedagógico para ofertar cursos a distância, ela organiza todos os documentos que são exigidos pela SEED - Secretaria de Educação à Distância, e elabora todo o planejamento educacional. Esse planejamento deve constar normas e procedimentos regulatórios que irão servir de base para a elaboração de todo projeto pedagógico para a criação de cursos e por fim, a sua destinação.

Vale lembrar que além de toda a documentação necessária, é preciso atender uma série de exigências para a manutenção destes cursos ofertados. São considerados elementos fundamentais:

1. Concepção de educação e currículo no processo de ensino e aprendizagem;

2. Sistemas de Comunicação;

3. Material didático;

4. Avaliação;

5. Equipe multidisciplinar;

6. Infraestrutura de apoio;

7. Gestão Acadêmico-Administrativa;

8. Sustentabilidade financeira.

Portanto, com essa elaboração minuciosa e bem detalhada, se dá o início do processo pedagógico para criação de um curso que será oferecido à distância, muito embora, não bastam apenas procedimentos administrativos para ofertar um curso. Os diversos modelos adotados por diversas instituições de ensino devem ser agregados as reais necessidades dos alunos até a região onde a instituição está instalada. Afinal, de que adianta um curso de Agricultura, por exemplo, numa localidade situada em meio às indústrias. Assim, identifica-se a necessidade coerente com as exigências legais. (JÚNIOR, 2015)

Em sua construção, o primeiro passo consiste em abstrair da realidade aquelas variáveis consideradas fundamentais, as quais, em sua complexidade, com suas interrelações e conexões, passam a integrar o modelo; e este é tanto mais satisfatório quanto maior sua capacidade de interpretar fielmente os fatos, inclusive antecipar fenômenos ainda não observados (COSTA, 2007, p.10)

Para o aluno distante, que experimenta sua primeira aula longe do professor, interessa pouco a maneira como imagens e sons estão chegando, e menos ainda as profundas teorias pedagógicas ou metodológicas que antecederam a transmissão ou a sessão privada do material entregue pelo curso. Ele quer assistir a uma boa aula, que lhe sirva de base para um processo de verdadeiro aprendizado. Ele quer ser seduzido pela 
informação, quer ser instigado a aventurar-se no mundo do conhecimento, e não ser conduzido pela mão a uma longa e tediosa jornada de imagens e sons tão sedutores quanto um pote de geleia. (GERBASE, 2006, p.2)

De acordo com Chaves (1999), no estudo sobre Tecnologia na Educação: Conceitos Básicos, "teleducação" tem que ver, necessariamente, com educação via imagens e não com educação via palavras ou via textos.

Teleducação, no sentido original e etimológico da expressão, pode ser perfeitamente bem realizada através de palavras (pelo rádio, por exemplo) ou por textos impressos (pelo computador), nada havendo na expressão que forçosamente inclua referência a imagens - a não ser para os desavisados, que associam o "tele" da expressão "televisão" e não a "distância" (CHAVES, 1999, p. 3)

Há instituições no ensino superior cujo projeto pedagógico foca mais a produção audiovisual e impressa pronta, não ao vivo. Produzem as aulas dentro do estúdio, com mais ou menos profissionalismo (MORAN, 2009). Já outras universidades que adquirem materiais prontos de empresas que organizam o conteúdo educacional e só retransmitem aos alunos. Por outro lado, existem instituições de ensino, que abraçam a causa e não se negam ao investir. Isso acontece, principalmente com as aulas transmitidas ao vivo por rede via satélite, e isso custa muito caro.

Portanto, é preciso que a instituição que está sendo analisada pense e remodele o projeto pedagógico. Principalmente na questão técnicas dos materiais pedagógicos, a fim de deixá-los mais atraentes e dinâmicos para que o aluno no processo da construção do conhecimento dele, ele não deixe de ver a aula, o que torna o material dispensável. EaD de qualidade é aquela que ajuda o aluno a aprender igual ao presencial. Não se mede isso pelo número de alunos envolvidos, mas pela seriedade e coerência do projeto pedagógico, pela qualidade dos gestores, educadores e mediadores, sejam tutores ou qualquer palavra que se use. (MORAN, 2009, p. 55)

Pela análise geral, pode-se concluir que há um longo caminho a ser percorrido e alguns desafios a serem vencidos: percebe-se que um número significativo de docentes ainda não dispõe das competências desenvolvidas nessa área. É correto afirmar que o processo comunicacional está tão alicerçado na aula presencial e seus métodos que muitos professores avaliam com certa descrença a utilização de tecnologia da informação e comunicação (TIC). Em outros casos, não há o mínimo de planejamento das aulas, o que resulta na forma inadequada da utilização de vídeos, como: tapaburacos, enrolação, deslumbramento, entre outros. (SILVA, 2011, p. 2) 
O medo da câmera e sua consequentemente inibição é a barreira mais difícil a ser vencida. Poucos ficam à vontade diante daquela lente, que é na verdade o olho do aluno que ninguém vê?, que não dá alento, muito menos o feedback tão necessário para saber se a aula está ou não atraindo a atenção, se está sendo ou não motivadora, ou se há compreensão ou dúvidas referentes ao conteúdo. (SILVA, 2011, p. 4)

O vídeo pode ser usado para exemplificar diversas situações porque ?consegue mostrar uma sequência de ações, closes, movimentos acelerados, perspectivas múltiplas? (MOORE; KEARSLEY, 2007). Porém, para que sua utilização seja eficaz e efetiva, é necessária a mediação pedagógica, capacitada e propensa a compartilhar conhecimentos e que estabeleça contextos interativos, de acordo com o público-alvo. (SILVA, 2011, p. 3)

A falta de criatividade é o maior problema. Para se pensar na forma e no conteúdo, o momento da criação do vídeo é um dos mais importantes. O saber e o como será feito são primordiais na hora de pôr em prática a conversa entre profissionais especialistas, professores e grupo acadêmico. Um bom roteiro pode ajudar neste sentido, embora, o professor na hora de gravar não pode ficar preso ao roteiro, pois senão a aula ficará engessada. Será nítido que o professor estará na frente da câmera lendo o texto que passa correndo na frente dele. $\mathrm{O}$ uso correto do vídeo irá resultar num vídeo muito mais atraente e agradável.

Outras formas de atualização, de troca de conteúdo e de ideias, com sugestões de melhoria no ambiente de trabalho e/ou críticas são as reuniões regulares com docentes, equipe técnica e de produção, e a aplicação de pesquisas de satisfação com os envolvidos no processo de produção da tele aula. Esse conjunto de ações, além de integrar as partes, faz com que todos participem do crescimento e da evolução da tele aula, garantindo a qualidade e o contentamento de todos. (SILVA, 2011, p. 6)

Duas linguagens diferentes não podem ser tratadas como se fossem a mesma. A analogia é óbvia: uma aula à distância não é uma aula presencial. Simplesmente adotar os procedimentos habituais de sala de aula, conforme fez o Professor X, é o caminho mais curto para o desastre pedagógico. (GERBASE, 2006, p.2,)

O mundo onipresente através de uma linguagem que independe do conhecimento de um idioma ou da escrita por parte do receptor. A TV mostra e o telespectador vê. Unindo mensagem visual à mensagem auditiva, o telespectador tem maior possibilidade de receber conhecimento. (PATERNOSTRO, 1994, p. 36) 
Muitas são as experiências do uso da imagem em movimento com finalidade educativa. No entanto é importante considerar que muitas dessas vivências optam por formatos ainda muito referenciados na dinâmica expositiva da aula presencial, e não levam em conta as características intrínsecas da narrativa audiovisual. É necessário também levar em conta a familiaridade dos alunos de $\mathrm{EaD}$ com produções televisivas e cinematográficas, o que implica numa noção, ainda que superficial, sobre alguns elementos constitutivos da gramática audiovisual. (CAVALCANTE, PONTES e RÊGO, 2009).

Novos aparatos técnicos, tais como videocassete, computador, mídias digitais, TV digital, multimídia e internet, retomam toda a teoria desenvolvida para o cinema tradicional e a televisão, e exigem um novo entendimento de suas particularidades. Videoaulas, audioconferências, teleconferências, animações interativas de autoinstrução e conteúdos multimídias em geral devem ser pensados tanto pelas teorias da linguagem audiovisual quanto pela ótica pedagógica-educacional. (MONTANARO, 2013, p.18).

Muito embora a concepção do vídeo precisa ser entendida que existem formatos e gêneros. Para Bonasio (2002, p.34), "a televisão deve ser feita não só por instinto, e sim com conhecimento, talento e responsabilidade". Para ele, além dos equipamentos é primordial conhecer as técnicas desenvolvidas por profissionais que dedicaram a vida à televisão por meio de suas experiências.

Uma boa ideia sozinha não é a garantia de comunicação de massa efetiva. É preciso saber como moldar uma ideia para encaixá-la em requerimentos técnicos e estéticos da mídia televisão. Esse processo de modelagem, conhecido como codificar, pressupõe um conhecimento profundo de ferramentas de produção como câmeras, lentes, iluminação, áudio etc. E também da estética aplicada como enquadramento correto de tomadas, usos específicos da cor, foco seletivo, uso da música, etc.(BONASIO, 2002, p. 35).

Críticas do uso das mídias audiovisuais no contexto de ensino aprendizagem advêm do fato desses sistemas de comunicação estimularem mais a percepção do que os mecanismos cognitivos de reflexão e análise. A lente da câmera com seus focos e desfoques, seus múltiplos planos, une-se a estratégias de edição e efeitos digitais e consegue dar à linguagem verbal vida e movimento, com isso, dinamiza, ilustra, completa e satura aquilo que na leitura ficava apenas a cargo da imaginação de cada um. A produção de vídeos didáticos há a tendência em se reforçar a informação visual e verbal, conferindo-lhes redundância suficiente para a compreensão e assimilação. (PENTEADO, 2001, p. 155, 157 e 159). 
De fato, não há um padrão pelo qual a $\mathrm{EaD}$ se apropria melhor ao vídeo. O que é preciso entender que o que é mostrado ao aluno deve ser muito mais bem preparado e elaborado. É preciso entender que a nova linguagem se encaixa e molda com as tecnologias que vão surgindo. Existem possibilidades de se fazer diferente e melhor, mas assim mesmo, existem restrições e soluções. Para Gerbase (2006, p.5), não é fácil produzir uma peça audiovisual para uma aula sobre um determinado tema. "O nosso desafio é produzir em escala, para dezenas de aulas, com dezenas de temas diferentes, e o mais importante, produzir com custos economicamente viáveis."

\section{METODOLOGIA}

De forma qualitativa, a pesquisa se baseia na produção do vídeo como ferramenta de aprendizagem e no processo de desenvolvimento destaca-se os erros e acertos. De forma subjetiva, a partir das experiências diárias, organiza-se o conhecimento. Ele se baseia na forma como observo o processo desenvolvido, destaco reuniões com maior frequência entre os envolvidos para produção das aulas por meio do vídeo, principalmente com participação massiva do professor, elemento fundamental para a realização das aulas, e parte acadêmica, aqui, tanto os profissionais do projeto acadêmico que vão ajudar na orientação dos trabalhos ao professor, quanto à equipe técnica do estúdio de TV, que irá munir o professor de informações com projetos práticos televisivos para untar a aula, ou ajudar na elaboração de outros processos para dinamizar as aulas.

A partir das análises dos textos lidos, do conhecimento empírico da presente pesquisa e na observação de vários modelos, identifica-se que o formato do vídeo gravado além de não permitir uma interação, já que é um vídeo não oferece recurso interativo, identificase que não é o melhor formato a ser usado na graduação e que temos que buscar soluções para fazer com que a aula seja mais visual e conseguir chegar mais próxima á área de estudo do aluno, que ela precisa ser de forma mais ilustrativa e interessante, e que de forma educativa, ela precisa ter o objetivo de potencializar a aprendizagem e favorecer a construção do conhecimento dentro do conceito de ensino-aprendizagem. Desta forma, chega-se ao fim desta pesquisa, muito embora não tenha esgotado o tema, as primeiras análises da um produto que é muito importante para a educação à distância, que é a ferramenta vídeo.

\section{RESULTADOS E DISCUSSÃO}

O vídeo como ferramenta para ajudar na construção do conhecimento é primordial no ensino-aprendizagem. Neste termo, a concepção do vídeo não pose ser somente uma 
transmissão de conteúdo. As aulas precisam ser mais e melhores produzidas com vários recursos visuais. Temos vários exemplos que podem ser migrados para da televisão para a tele aula ou videoaula, pois imagem e som são recursos audiovisuais que enriquecem qualquer material visual. Mas é importante fazer uma ressalva. Os modelos encontrados hoje são ultrapassados e não possuem interação. Ou seja, o aluno assiste a tele aula, mas a interação dele somente ocorre por meio da plataforma. Sem falar que muito conteúdo já está defasado.

$\mathrm{Na} E \mathrm{ED}$, o vídeo é apresentado como ferramenta facilitadora da compreensão, leitura crítica da informação, na qual a problematização esteja presente. Provoca debates, sensibiliza, ilustra, complementa informações, levanta sugestões dos alunos e dinamiza as aulas. (SILVA, 2011, p.3)

A questão fundamental aqui é que há uma proximidade inerente da modalidade de educação à distância com as diferentes tecnologias de informação e comunicação. Afinal, se ensinar e aprender em diferentes espaços e tempos dependem fundamentalmente de uma interface e ao mesmo tempo, estas novas ferramentas de comunicação criam exatamente estratégias para esse diálogo, parece natural esta relação direta e o desenvolvimento de sua linguagem específica. (MONTANARO, 2013 p.19)

Quanto a equipe técnica além de atualização devido a transformações tecnológicas, precisa estar mais antenada com as mudanças nos projetos pedagógicos propostos pela universidade de modo que a produção televisiva seja apropriada, pois, em muitos casos, acontecem novos cursos, novas disciplinas e o estúdio sem o preparo adequado acomoda-se com a situação existente e não consegue propor novas transformações. É preciso que a universidade invista em equipamentos para atender as altas demandas e para oferecer melhores aulas já que tem se a ideia de levar as aulas para gravações externas e hoje encontramos dificuldades para a elaboração de novos modelos.

\section{CONSIDERAÇÕES FINAIS}

É notório que qualquer pesquisa que analisa um fato, propõe mudanças, pois encontram problemas ou melhorias. Como vimos as aulas gravadas como referências para material pedagógico apresentam falhas, pois como visto por diversos autores, o modelo adotado pela universidade estudada, é considerado ultrapassado. Não que ele seja certo ou errado como já mencionado, mas na busca de qualificar o material é necessário que haja planejamento e condições para desenvolver melhorias. 
É preciso investir nos equipamentos do estúdio TV, oferecer melhores ferramentas para que as aulas sejam melhores produzidas. É preciso capacitar equipe técnica e pedagógica dando melhores suportes, condições e aperfeiçoamento. É preciso também investir no professor, personagem principal no elemento no ensino-aprendizagem. DarIhe condições e tempo de preparar o material e subsídios para ajudá-lo na gravação, pois essa não é área dele. E qualquer dificuldade que ele tiver, ele por meio da sua feição, fala e gestos irão passar isso no vídeo, e o aluno que está do outro lado, irá sentir a insegurança do professor frente às câmeras.

Podem se encontrar vários benefícios com melhores ferramentas ofertadas. Aulas mais atraentes, alunos motivados, professores capacitados, profissionais inovadores, que pensam e desenvolvem em cima de novos desafios. Portanto, é preciso que a universidade invista em produção, em estrutura e em pesquisa. Não basta apenas querer inovar com tecnologia porque é necessário. É preciso investir porque existe necessidade de ser feito.

\section{REFERÊNCIAS}

ALVARENGA, Marina. Metodologia Cientifica. Universidade Braz Cubas, Mogi das Cruzes, São Paulo, 2014.

BONASIO, Valter. Televisão: Manual de Produção \& Direção. Editora Leitura, 2002

CAVAlCANTE, Andrea Pinheiro Paiva. A Linguagem Telejornalística no Ensino a Distância: Um Estudo de Mídia-Educação, 2009

CHAVES, Eduardo. Tecnologia na Educação: Conceitos Básicos, 1999. Disponível em

COSTA, Celso José. Modelos de Educação Superior a Distância e Implementação da Universidade Aberta no Brasil. Revista Brasileira de Informática na Educação, v. 15, n. 2, 2007.

GERBASE, Carlos. Desafios na construção de uma estética audiovisual para educação à distância (EAD). Revista Logos 24: cinema, imagens e imaginário. Ano 13, 1ํㅜㄴ semestre, 2006.

JÚNIOR, Arlindo Fernando Paiva de Carvalho. Educação a Distância: Uma Análise dos Modelos de Ensino. p. 1-9, 2013. 
MARTINS, Dyêgo Marinho. ET. AL. Vídeos Educativos no Ensino Superior: O Uso de Videoaulas na Plataforma Moode. Revista Paidéi@. Unimes Virtua, v. 5, n. 9, 2014. Disponível em http://revistapaideia.unimesvirtual.com.bracessado em Outubro 2015.

MAZZEU, Ian Rittmeister. Produção de Videoaulas para EaD: Contribuições para o Diálogo com os Educando, 2012.

MINIDICIONÁRIO Aurélio, Nova Fronteira, 1977.

MONTANARO, P. R., A Caracterização da Produção de Materiais Didático-Educativos Audiovisuais para Educação Superior a Distância na UFSCar, 2010. Dissertação (Mestrado) Universidade Federal de São Carlos, São Carlos, 2013.

MOORE, M.; KERASLEY, G. Educação a Distância: Uma Visão Integrada. São Pauo:Thomson Learning, 2007.

MORAN, J. M. Modelo e Avaliação no Ensino Superior a Distância no Brasil. Disponível em Acesso em: Setembro 2015

PATERNOSTRO, Vera Íris. O Texto na TV: Manual de Telejornalismo. Rio de Janeiro: Campus, 2006.

PENTEADO, Heloisa Dupas (org) Pedagogia da Comunicação: Teorias e Práticas. São Paulo. Cortez, 2001.

SILVA, Patricia Rodrigues. A Importância da Capacitação do Professor na Apresentação das Teleaulas e Utilização na Produção Audiovisual em EaD. 2011

SILVA, Patricia Rodrigues. Videoaula Objetivas e com Exemplos Práticos são Preferência de Alunos. Disponível em

SOUZA, José Carlos Aronchi de. Gêneros e formatos na televisão brasileira. São Paulo: Summus Editorial, 2004. 